\title{
Randomness and the Madness of Crowds
}

\author{
Utz Weitzel and Stephanie Rosenkranz
}

\begin{abstract}
Human interaction often appears to be random and at times even chaotic. We use game theory, the mathematical study of interactive decision making, to explain the role of rationality and randomness in strategic behavior. In many of these situations, humans deliberately create randomness as a best response and equilibrium strategy. Moreover, once out of equilibrium, individual beliefs about the real intentions of others introduce significant randomness into otherwise quite simple and deterministic situations of interaction. In a second step we discuss the role of randomness on financial markets, which are prototypical institutions for the aggregation of individual behavior. As in certain simple games, financial markets can produce outcomes that are close to perfect randomness. In fact, random walks in financial returns are considered by most scholars to be efficient and desirable. Finally, we apply game theoretical insights to behavior on financial markets and show how strategic speculation on 'greater fools' can create a 'madness of crowds' that often ends in chaotic swings, bubbles and crashes.
\end{abstract}

\section{Introduction}

In 1720, Sir Isaac Newton was heavily invested in the South Sea bubble. When the stock bubble burst he lost a fortune of about $£ 2.4$ million (in present day terms) and was quoted as stating: "I can calculate the movement of the stars, but not the madness of crowds".

\author{
U. Weitzel ( $\square)$ \\ Department of Economics, IMR, Nijmegen School of Management, \\ Radboud University, Thomas van Aquinostraat 5.1.26, 6525 GD Nijmegen, \\ The Netherlands \\ e-mail: u.weitzel@fm.ru.nl; u.weitzel@uu.nl \\ U. Weitzel · S. Rosenkranz \\ Utrecht University School of Economics, Kriekenpitplein 21-22, \\ 3584EC Utrecht, The Netherlands \\ e-mail: s.rosenkranz@uu.nl \\ (C) The Author(s) 2016 \\ K. Landsman and E. van Wolde (eds.), The Challenge of Chance, \\ The Frontiers Collection, DOI 10.1007/978-3-319-26300-7_4
}


The interaction between humans does indeed often appear like madness, governed by error and randomness. There is, however, a scientific field that attempts to logically explain human interaction. Game theory is the mathematical study of interactive decision making and it has revolutionized the way we see and understand economics, politics, financial markets, and many other aspects of human society. Game theory also applies to other species than humans and has made important contributions in, for example, biology.

This chapter will introduce simple game theoretical concepts and financial market applications to explain how we interact in certain situations and what role randomness plays in our behavior. The central question is how people deal with strategic uncertainty, which is the uncertainty about other people's expectations and actions that we face in human interaction. We then apply this approach to financial markets and discuss how heterogeneous beliefs and errors in updating can create feedback cycles and the 'madness of crowds' Newton referred to.

\section{Super-Humans Against Nature and the Rationality Assumption}

\subsection{A Single Random Event}

Imagine a very simple game against nature.

Coin toss: First, human bets on one side of the coin, heads or tails. Then, in the coin toss, nature shows one side of the coin. ${ }^{1}$

Many people see the throw of a dice or a coin toss as a prime example for natural randomness. For at least 5000 years, our ancestors used randomization devices. ${ }^{2}$ But is a coin toss really random? This goes back to an age old discussion culminating in the question whether the world is predictable or unpredictable; whether everything is predetermined, or whether nature is inherently stochastic. During the Age of Enlightenment and the Industrial Revolution, Isaac Newton's advances in mechanics suggested that the universe is predictably governed by simple physical laws. This lead to the lofty notion that, one day, humans might be able to take full control over their fate with a world formula. In 1814, the French astronomer and mathematician

\footnotetext{
${ }^{1}$ Another example of such a situation is a farmer who decides at the beginning of a year whether to plant crops or not (human places a bet). There is an equal chance that the weather this year is good or bad for crops (toss of a coin). It is up to nature to determine the outcome.

${ }^{2}$ The oldest known dice were part of an 5000-year-old backgammon set, excavated at the Burnt City in southeastern Iran. In ancient times the outcome of a throw of a dice was seen as the decision of God. Consequently, dice were frequently used in important decisions.
} 
Pierre-Simon Laplace famously described the idea of scientific determinism as a perfect intelligence for which there exists no uncertainty (Laplace 1814). ${ }^{3}$

Laplace's Demon, as his notion became known, comes close to the definition of rationality in game theory. A completely rational agent is a super-human, an artificial construct that comes in handy when economists and game theorists need to build models. Like Laplace's Demon, this super-human knows everything ('perfect knowledge') and can compute even the most complex problems with lightning speed. Another feature of this super-human is that she always strives to maximize her own utility. ${ }^{4}$

In Laplace's scientific determinism, a coin toss is a quite boring affair. So would be Roulette or wheels of fortune. A super-human would simply know what side of the coin nature would show and bet accordingly. Scientific determinism remained the official dogma throughout the 19th century. This drastically changed with the 'probabilistic revolution in physics' initiated by statistical mechanics in the mid nineteenth century and continued by quantum mechanics in the early twentieth century (see Lüthy and Palmerino in this book).

But even without assuming unpredictable quantum states in quantum systems we may not be able to forecast with certainty, even in Laplace's deterministic world. Early works, for example, by Henry Poincaré have shown that, in deterministic systems, infinitesimally small changes in starting conditions can produce unpredictable outcomes. ${ }^{5}$ This insight is the foundation of deterministic chaos theory and it took nearly a 100 years for the 'chaos revolution' to fully unfold. In the late 1960s, the MIT meteorologist Edward Lorenz discovered what is commonly referred to as the 'butterfly effect'. ${ }^{6}$ In the 1970 s, several mathematicians proved that simple nonlinear dynamic systems can produce irregular long run behavior and chaotic behavior without external random disturbance (Ruelle and Takens 1971; Li and Yorke 1975). ${ }^{7}$ In nonlinear dynamic systems, predictions about the future become progressively worse when we do not have absolutely perfect knowledge of the initial

\footnotetext{
${ }^{3}$ See the contribution of Lüthy and Palmerino in this book for a more detailed discussion.

${ }^{4}$ Utility maximization is a tricky concept, which many mix up with ruthless money-making and egoism. First, utility is more than simply making money. Feeling happy, receiving love or any other positive sensation can also be a utility that people strive to maximize. This all depends on personal preferences. Given a choice between money and friendship, one person might prefer the former and another the latter. Second, a human can gain satisfaction (utility) from helping others. Did Mother Teresa only help others or also herself? Hence, being 'altruistic' can be perfectly in line with the definition of own utility maximization and rationality.

${ }^{5}$ In 1887, king Oscar II of Sweden promised a prize for the best answer to the question 'Is our solar system stable?' Poincaré showed that the motion in a simple three-body system - such as sun, earth and moon - that interact through gravitational attraction, can be sensitively dependent on initial conditions and become highly irregular and unpredictable.

${ }^{6}$ Lorenz and his team were running weather simulations on a computer and suddenly realized that rounding errors in the third decimal of just one measurement in one corner of their map (a 'flap of a butterfly') were able to change predictions in another area from clear skies to thunderstorms.

${ }^{7}$ A well-known application is logistic population growth in biology (May 1976).
} 
state. Thus, even after the discovery of quantum physics, chaos theory re-introduced indeterminism 'through the back door' and at a surprisingly fundamental level. ${ }^{8}$

We will come back to deterministic chaos in complex systems in Sect. 5.3. For the time being, it is important to note that, according to quantum physics, but also to chaos theory, even a perfectly rational Laplacian super-human-without any restriction in knowledge and cognition-would approach a simple coin toss against nature in the same way as normal humans would: as a game of pure chance. This is in line with game theory where a perfectly rational agent is still exposed to randomness. When facing a coin flip, a rational decision maker, even when equipped with perfect knowledge, will not know whether the outcome will be head or tails.

\title{
2.2 Repeated Random Events
}

Fortunately, once faced with many independent coin tosses, our perfectly rational super-human can forecast the future very well.

\begin{abstract}
Repeated coin toss: We start with no money and every minute nature offers us a coin toss where we can either win one dollar (heads) or lose one dollar (tails). Our lifetime wealth then develops according to what is known as a 'random walk': we start at zero and might win a dollar, then another dollar (two dollars of wealth), then we may lose five dollars in a row (minus three dollars wealth), but then we win some money again, and so on.
\end{abstract}

What is our average lifetime wealth? According to the law of large numbers and the central limit theorem we can be almost certain to have earned an average of zero. Why? We have an equal chance to win or lose one dollar, on average, zero dollar. With millions of coin tosses, the gains and losses almost perfectly cancel each other out. On average, we expect to gain or lose nothing. We therefore also say that the expected value of such a coin toss is zero.

There is a catch, however. An expected value of zero dollar does not mean that we actually receive zero dollar. The expected value of a single coin toss is zero, but we still know for sure that the outcome will not be zero. Equally, just because we know that the average wealth over our life time is going to be very close to zero, our final wealth at the end of our life-time will most probably not be zero. In fact, our final wealth will probably be substantially above or below zero. Our final wealth is not an average but a single realization and it is impossible to predict this exact point. Hence, even if we are confident in predicting averages, we are not very good at exact point predictions.

Figure 1 shows this intuitively with a Galton board, named after the English scientist Sir Francis Galton. The horizontal position of the red ball dropped into the Galton board represents the wealth level and the pegs represent the coin tosses. Every time the red ball hits a peg there is an equal chance to fall to the left hand side (loss of one dollar) or the right hand side (gain of one dollar). Each red ball follows

\footnotetext{
${ }^{8}$ We thank Klaas Landsman for valuable contributions to this and the previous paragraph.
} 


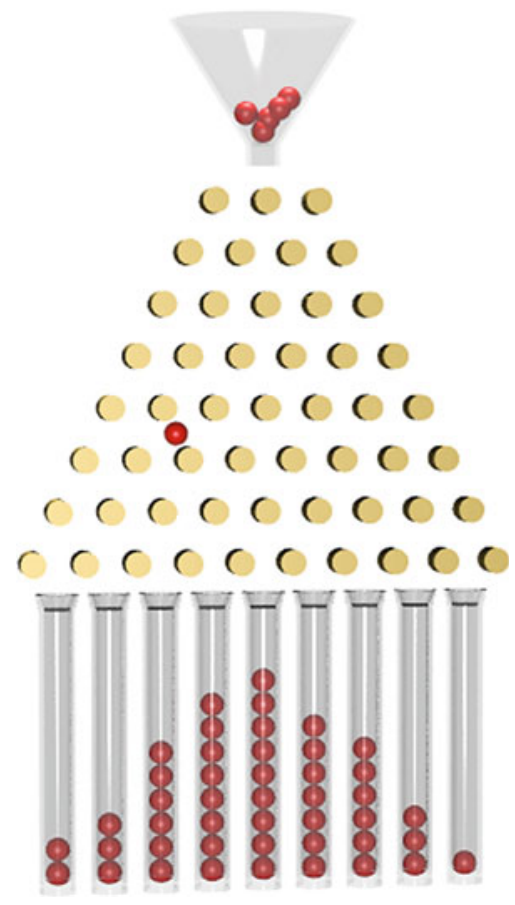

Fig. 1 Galton board

a random walk and many of these random walks (red balls) produce a binomial distribution of final wealth levels, as approximated by the distribution of red balls at the bottom of the Galton board. As binomial distributions are symmetric, the expected value of random walks, the average, is zero (the middle slot at the bottom). The large majority of the red balls, however, does not land in the middle slot. Therefore, although we can be quite sure to expect an average of zero wealth, individual final wealth levels are most probably not zero and the exact final wealth level (final slot) of one single ball is unpredictable.

\subsection{Risk Preferences}

How much would we bet on a single coin toss against nature in which we can win or lose one dollar? This depends on our risk preferences. The expected value is zero, so if we are risk-neutral we should offer the expected value, which is zero. This makes us indifferent between playing the game or not. But we might be risk-seeking. As the final wealth level of a single coin toss is certainly not zero, we might want to bet on the positive outcome of the coin toss and pay anything from 1 to 99 cents for playing the game. How much we are willing to pay for playing the 
coin toss is an indication of our risk-seekingness. Conversely, we might have a preference to prevent losses and to - at least partially — safeguard our current wealth level. In this case we are risk-averse and we require nature to pay us some amount from 1 to 99 cents to take the risk (play the game). The more risk averse we are, the more attractive nature must make the game for us to accept it. So, how much we are willing to pay/accept to play the game depends solely on our personal risk preferences. This also applies to fully rational super-humans. We assume that personal preferences are given and stable, but heterogeneous across individuals. Rational players are not necessarily risk-neutral. They can have any risk preference and maximize their payoff conditional on their preference. Moreover, we can have different types of preferences, not only for risk, but also for altruism or equality or with regard to other economic and social dimensions.

\section{Super-Humans Against Super-Humans}

The crucial characteristic of fully rational super-humans is that they have perfect knowledge about the rules of the game and know that this also applies to all other players, including the knowledge that they are also fully rational. The latter is called the 'common rationality assumption'. Given this definition of rationality, let's see what happens if two super-humans play the following game.

Centipede game: Two super-humans, Superboy and Supergirl, play ball with each other. Nature randomly gives Supergirl the ball. She can decide to throw the ball to Superboy, or not. If she passes the ball, Superboy can decide to throw it back, or not. The game is finished either after 100 passes or if one of the two players decides not to pass the ball anymore. Nature also puts a number on the ball and increases it by 10 with every pass. When Supergirl gets the ball from nature, the number on the ball is 10 . After the first pass, Superboy catches a ball displaying 20 on it. With the next pass the number changes to 30 , and so on. If a player decides not to pass the ball, s/he gets the number on the ball paid out in dollar and the other player gets the same number divided by 10 . Hence, the holder of the ball receives $10+n \times 10$ dollar and the other player $(10+n \times 10) / 10=1+n$ dollar after $n$ passes.

Assuming that both players prefer to earn some money over nothing at all, how many passes do we observe between the two players? In game theory, analyses typically start at the end and then move backwards to the beginning. This is what we call 'backward induction'. After 100 successfully completed passes, Supergirl will get the ball back and receive 1010 dollar. But Superboy can see this coming and therefore does not pass the last ball back. Then Superboy gets 1000 dollar and Supergirl 100. Knowing this, Supergirl would not even pass the second-to-last ball to Superboy. Knowing this, Superboy would not make the pass before that one, and so on. Hence, when Supergirl receives the ball from nature, she does not even do the first pass and takes the 10 dollar. Superboy receives one dollar. 
Supergirl's behavior is an equilibrium strategy. Under the common rationality assumption, Supergirl knows the equilibrium strategy of Superboy (keeping the ball) and she cannot benefit from changing her chosen strategy, while Superboy keeps his strategy unchanged. This applies to both players as none of the two players would pass the ball if randomly chosen by nature as first receiver. The current set of strategies and the corresponding payoffs constitute a Nash equilibrium, named after the mathematician and John Nash. ${ }^{9}$

Backward induction is often not very intuitive, which is one of the reasons why we have to assume super-humans. In many games only super-humans are actually able to 'see' the end of the game, keep it in mind, rationally backward induct, find the game-theoretical equilibrium strategy and finally play the corresponding equilibrium behavior flawlessly right from the beginning. Also, under the common rationality assumption we assume that everybody in the game is a super-human and everybody knows this. This takes all randomness out of the centipede game. Does this mean that randomness never plays a role for super-humans and always leads to determinism unless a mechanistic randomization device is introduced? Not quite. The point is that Supergirl may know everything about Superboy's reasoning, preferences and incentives, but this does not mean that Superboy's actions are always predictable. In fact, there are games where fully rational players want to be as unpredictable as possible.

Rock-Paper-Scissors: Supergirl and Superboy simultaneously choose either Rock, Paper or Scissors. Rock beats Scissors, Paper beats Rock, Scissors beats Paper.

Each strategy has a $1 / 3$ chance to win, $1 / 3$ chance to draw and $1 / 3$ chance to lose. If Supergirl thinks that Superboy always plays Rock she could beat him with always choosing Paper. But this is not a Nash equilibrium as Superboy could improve on this strategy set by always choosing Scissors. This, again, would lead Supergirl to always choose Rock, and so it goes round and round. The only equilibrium strategy in this situation is to mix the three options as randomly as possible in order to win a least in $1 / 3$ of all tries, draw in $1 / 3$, and lose in $1 / 3$. So, the solution to this game is to play sequences that are perfectly random and unpredictable, just like a three-sided dice would be.

This is harder than we think. Humans are not very good at simulating random patterns. For example, in 'randomizing' we often underestimate clustering. This is the so-called gambler's fallacy, which describes the phenomenon that humans tend

\footnotetext{
${ }^{9}$ It does not make a difference if the two players communicate with each other. Whatever Superboy promises, he cannot commit to it. Therefore his answer is cheap talk. In fact, given his monetary preferences he has a clear commitment to keep the ball, because this maximizes his payoff. Knowing this, Supergirl will keep the ball even if Superboy promises to pass it back.
} 
to expect a coin toss to show tails with a higher probability after a sequence of heads (Tversky and Kahneman 1971, 1974). In other situations we may fall prey to the hot-hand-effect (Gilovich et al. 1985). Here, we tend to believe that a series of heads indicates a higher likelihood of heads in future coin tosses. ${ }^{10}$

Of course, Supergirl and Superboy can randomize perfectly so that both win, draw and lose with equal probability over the long run. But as a thought experiment, let's take the Laplacian view to the extreme and see what would happen if fully rational super-humans would really know everything with absolute certainty. What would happen if the brains of two players are two completely transparent randomization devices (we basically see all neurons fire) and both players are able to perfectly anticipate - as a point prediction - what the other side will choose in the next round? In this situation, the only equilibrium strategy for both players would be to always play the same as the other so that every game ends in a draw. ${ }^{11}$ But what happens if a draw is not an option?

Matching pennies: Supergirl and Superboy each choose either heads or tails simultaneously. So, they both toss a virtual coin. Supergirl wins if the two coins match (heads and heads or tails and tails). Superboy wins in all other cases (coins do not match).

As in Rock-Paper-Scissors the Nash equilibrium is a mixed equilibrium strategy where both players have to perfectly randomize in order to win/lose half the time. Draw, however, is not an outcome. Thus, if super-humans could perfectly look into each other's brains, both players would constantly point-predict the opponent's intention for the next move, update, change their own intentions and point-predict again, only to realize that the opponent's intention has changed accordingly, and so on. In this setting, both players are frozen in an infinite optimization without the ability to act. This may be where free will or emotions are ultimately needed as 'circuit-breaker'. It may be that "to make a decision, emotion is the necessary trigger (and) without emotion, one would be reduced to the state of an idiot savant who goes on endlessly calculating without the ability to make a choice" (Olsen 1998).

\footnotetext{
${ }^{10}$ This phenomenon is found in sports, where people falsely attribute skill to a random series of wins and therefore believe that the team will win again. The same also applies to the believe that random successes in the past in investment performance will continue in the future. The hot-hand-effect applies less to situations where people have to randomize themselves, but more to situations where people have to correctly 'read' or identify random patterns produced by others. ${ }^{11}$ In terms of payoff it would not even matter whether two super-humans always play draw or perfectly randomize and win, draw and lose equally often. All that matters is that both know with certainty which of the two meta-strategies they will play: a perfect point-prediction of each other's next draw or a perfect randomization across the three options rock, paper, and scissors.
} 


\section{Humans Against Humans}

\subsection{Bounded Rationality}

Rationality requires extreme assumptions concerning players cognitive abilities: perfect knowledge about all factors that affect the decision to be taken - so basically about everything - and virtually infinite computing abilities to derive rational expectations forecasts and optimal decisions. Needless to say that we are no super-humans. And needless to say that no economist seriously believes that human behavior is always fully rational. Rationality is only a benchmark model, but a very powerful one. It allows us to analyze benchmark behavior, which, under evolutionary pressure and over time, is theoretically more successful in dealing with nature and its randomness than any other model. Nevertheless, it is far from present in every human, in all situations, or at all times. In the 1950s, Herbert Simon advocated the concept of bounded rationality, a more realistic description of human behavior where agents have limited computing capacities and information (Simon 1955). Instead of perfectly optimal decision rules, boundedly rational players use short-cuts, rules of thumb, or so-called heuristics to overcome 'uncomputable' problems. These heuristics are not necessarily optimal or perfect but in complex environments they may perform reasonably well (for a discussion see Gigerenzer and Selten 2002). By using heuristics we inevitably make mistakes, which may be random but can also be biased.

\subsection{Beliefs}

As we cannot know everything, we are uncertain about the actions and beliefs (and beliefs about the beliefs) of others. This is commonly referred to as strategic uncertainty. Let's assume that Superboy and Supergirl in the above ball game (centipede game) can actually make mistakes. In other words, they are not super-humans anymore but simply humans: Girl and Boy. Let's also assume, that Girl, who received the ball from nature first, actually passes the ball to Boy. Remember that this is a move that super-humans would never do because it is no Nash equilibrium. However, as we now look at humans, there is a possibility that Boy receives the ball and suddenly has to form a belief about Girl's motives for passing the ball. Here are some beliefs that Boy might hold about Girl:

1. Girl violates rationality and made a mistake. She passed the ball, because she simply did not understand the game properly. She did not backward induct and did not realize that passing the ball in the first place is not fully rational.

2. Girl has other preferences (other than purely monetary ones). Maybe she passed the ball because she is altruistic and actually wants Boy to get the profit from the game. So, Girl actually gets more utility out of giving Boy the profits than keeping the ball and the money to herself. 
3. Girl aims for a more efficient outcome. As the pot is increasing for both with every pass, Girl might expect that Boy colludes with her against nature. After the last pass, Girl and Boy would have extracted the highest possible profit from nature. For this, however, Girls would have to believe that Boy passes the last ball back to her (or have altruistic preferences).

Of course, the dilemma of the situation is that Boy does not know what Girl's underlying motivation was when she passed the ball. Boy has to form a belief about Girl's intentions, but he cannot know for sure. To make matters worse, in a world of many players, there are many possible beliefs and weighted mixtures of beliefs about each other's underlying motivations.

With certain assumptions, game theory can deal with these situations. For example, let us assume that all deviations from the rational equilibrium are because of the first of the above reasons. If people make independent and unbiased mistakes and we know about this, then Boy can compute how probable it is that Girl makes another mistake. ${ }^{12}$ If players believe in a sufficiently high error rate, they end up in a 'Quantal Response Equilibrium' (QRE) of passing the ball at least once (McKelvey and Palfrey 1995, 1998). In fact, experimental evidence shows that the vast majority of people pass the ball more than once. Repeated rounds of this game also show, however, that the experienced error rate in the population in early rounds feeds into people's behavior in later rounds, which can then be explained quite rationally in a QRE sense (McKelvey and Palfrey 1992).

The basic reasoning in the centipede game is not restricted to sequential moves but can also take place in a one shot decision as the following example shows.

Guessing game: Every person in a larger group is asked to privately pick a number from 0 to 100 and write it on a piece of paper. An experimenter collects the numbers and computes the average. The person with the number that is closest to $2 / 3$ of the group average wins. These rules are known to everybody before they pick the number (Moulin 1986).

Let's assume that everybody in the room (except you) randomly picks a number. Then the group's average would be 50 and you would pick $2 / 3 * 50=33$. If everybody thinks that, everybody would pick 33 and you should pick $2 / 3 * 33=22$. Then again, if everybody does that you should pick $14 . \overline{6}, 9 . \overline{7}, 6.5$ etc. until you reach 0 . Depending on their number, players exhibit distinct, boundedly rational levels of cognitive reasoning (Nagel 1995). Players with no level of reasoning ('Level 0 ') pick a random number, 'Level 1' players pick 33, 'Level 2' players pick 22, and so forth. In experiments, most players reveal firstand second-order depth of reasoning (Nagel 1995; Camerer et al. 2004).

Under the common rationality assumption, there is no strategic uncertainty about the others. Hence, if all players have an infinite level of reasoning, all players

\footnotetext{
${ }^{12}$ Of course, it might also be that Girl did not make a mistake at all but instead assumed that Boy would make a mistake. She might have passed the ball in the expectation that Boy erroneously passes it back. Hence, if we assume mistakes, observing a 'mistake' might not actually be a real error, but rational speculation on the other side making one. See Osborne (2003) for a discussion on this.
} 
choose the number 0 , which is the Nash equilibrium of this game. Zero is the only value where everybody in the group can win.

In a QRE-world, however, where we believe that some of us makes mistakes, 0 would not be a best response or equilibrium. We would have to pick a positive number, but which one exactly solely depends on our belief about the error rate of the other people in the group. Thus, to win this game in the real world, rational players should not choose the theoretical Nash equilibrium but a positive number. Interestingly, when doing so, we cannot tell anymore from the outside whether the winner was extremely rational or made a mistake and was simply lucky.

There are several other models that try to explain the real-world deviations from the Nash equilibrium in both the centipede and the guessing game (a.k.a. beauty contest). Cognitive hierarchy models, for example, assume that each player has a finite depth of reasoning and believes that $\mathrm{s} / \mathrm{he}$ is the most sophisticated player in the game. Thus, in the guessing game, a Level 2 player will assume that all others are Level 1 and therefore choose 22. A Level 3 player expects all others to be Level 2 and chooses $14 . \overline{6}$, and so on. ${ }^{13}$ Another branch of game theory, referred to as 'global games', attempts to deal with the second of the above reasons (other preferences), by assuming various simultaneous payoff structures that each player may face with a certain probability (Carlsson and Damme 1993).

In essence, all models advance possible ways how certain beliefs about other players' actions and beliefs are formed. Depending on these beliefs, practically all out-of-equilibrium outcomes can be reached. However, as all models plausibly describe experimentally observed outcomes, we still lack a fundamental understanding of belief formation processes. How are initial beliefs (priors) about others are formed under strategic uncertainty? How quickly do people learn and in which way? ${ }^{14} \mathrm{~A}$ common assumption is that people form expectations and update their beliefs about the real state of the world according to some learning scheme (Sargent 1993). Many studies in neuroscience, particularly in the area of sensorimotor control, suggest that our brain is a Bayesian prediction machine. ${ }^{15}$ We would not be able to catch a ball without continuous forecasting and updating of priors about its most likely trajectory (Doya 2007). When it comes to cognitive processes, however, other studies have shown that we are not very good at Bayesian updating. For

\footnotetext{
${ }^{13}$ In the centipede game, if Girl is Level 0 (non-strategic), she will compare the payoffs at each possible endpoint of the game. As the pot is increasing for both with every pass, she will note that her highest reward results from Boy passing the ball on the final round. Girl will thus choose to always pass the ball. If Girl is Level 1, she will note that this outcome is not feasible for Boy on the last round and choose not to pass the ball on her last round. If Girl is Level 2, she expects that Boy is Level 1 and that he will, therefore, anticipate her ending the game on her last round. She therefore chooses to end the game on the second to last round, and so on.

${ }^{14}$ For example, in the centipede game, assume that Boy believes Girl is rational, but then he suddenly gets the ball. How did Boy come to his initial belief in the first place, and how does he adapt his belief given that Girl did not behave accordingly?

${ }^{15}$ Also see the chapter of Bekkering, van Elk and Friston in this book.
} 
example, in the assessment of probabilities, people have been shown to neglect base rates (Kahneman and Tversky 1973). In stock markets, investors seem to over- and under-react to different types of news (De Bondt and Thaler 1985). Alternative models, for example, reinforcement learning and adaptive learning of simple forecasting heuristics or anchor and adjustment processes, are cognitively less demanding and allow for more errors (Kahneman 2003; Tversky and Kahneman 1974; Hommes 2013). At the extreme end of the spectrum, some psychologists argue that beliefs come first and that the brain is nothing more than a chatterbox that rationalizes beliefs ex post. The brain looks for patterns in sensory data and infuses them with meaning, forming beliefs. Then, it primarily focuses on the selection of confirmatory evidence that reinforces those beliefs in a positive feedback loop. ${ }^{16}$

\subsection{Speculation}

With heterogeneous beliefs and different levels of reasoning, speculation comes into play. We focus on financial speculation, which aims at making a profit from price movements in a market, even if these price movements are completely unrelated to the fundamental value of the underlying asset or its proceeds (e.g., dividends or interest). ${ }^{17}$ This can be seen in the following adaptation of the centipede game from (Moinas and Pouget 2013).

Bubble game: An asset, commonly known to have no fundamental value, is traded in a sequential market with three traders. At each point in the sequence, an incoming trader has two choices. S/he can either accept a buy offer at a given price and offer it to the next trader in line at a higher price, or s/he can reject the buy offer, which leaves the current owner stuck with a worthless asset. The last trader in the sequence cannot sell the asset anymore. Thus, when traders buy the asset, they effectively speculate on not being last and on being able to sell it to the next trader at a higher price. Traders do not know their position in the market sequence. They do, however, receive a signal about their position. This signal is the price of the asset that has been offered to them. The higher the offered price the higher the probability of being last in the sequence.

Figure 2 shows a graphical representation of the game. All traders receive one dollar initial capital. Trader 1 is offered to buy the asset at a randomly drawn price $P_{1}$ by nature. ${ }^{18}$ Trader 1 does not know whether the offer comes from nature or a

\footnotetext{
${ }^{16} \mathrm{~A}$ recent bestseller of psychologist and science historian Michael Shermer has popularized this view (Shermer 2012).

${ }^{17}$ Despite many disadvantages and public criticism, speculation also has positive functions, for example, to provide liquidity in financial markets, which makes it easier or even possible for others to offset risk.

${ }^{18}$ As the random price can be above 1 dollar, we assume that a financial partner (who is not part of the game) provides each player with sufficient capital to be able to buy the asset. When selling the asset the financial partner gets all the profits except for 10 dollar which the trader receives.
} 


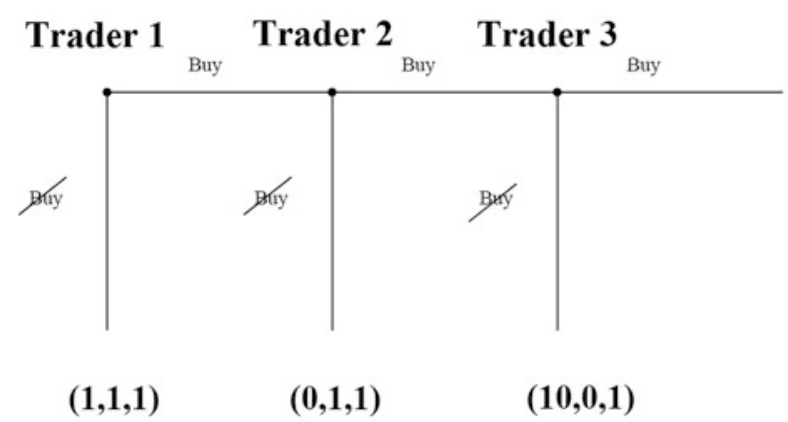

Fig. 2 Bubble game (extensive form)

previous trader (as s/he does not know her position in the sequence for sure). ${ }^{19}$ When Trader 1 rejects the offer the game ends and all traders earn one dollar of initial capital. When Trader 1 accepts the offer, the asset is offered to Trader 2 at a price $P_{2}>P_{1}$. When Trader 2 rejects, the game ends: Trader 1 earns nothing and Trader 2 and 3 each earn their initial capital (one dollar). When Trader 2 accepts, Trader 1 successfully sells the asset and earns 10 dollar. Trader 2 then offers the asset to Trader 3 at $P_{3}>P_{2}$. When Trader 3 rejects, the game ends and Trader 2 is stuck with the worthless asset (Trader 1 gets 10 dollar, see above). As Trader 3 does not know for sure whether s/he is last in row she might buy the asset, but will be unable to resell. In this case Trader 3 gets nothing and Trader 1 and 2 each enjoy 10 dollar profit from successful reselling.

The Nash equilibrium of the bubble game is very similar to the centipede game: due to backward induction no trader should buy the asset. Thus, the first, randomly drawn price $P_{1}$ of the asset will not be accepted by Trader 1. Accordingly, the market value for the asset is equal to its fundamental value, namely 0 . In their experiments, however, Moinas and Pouget (2013) find substantial trading of this worthless asset and the formation of significant price bubbles. Theoretically, the QRE povides the best explanation for this buying behavior (Moinas and Pouget 2013). Traders seem to believe that their fellow traders down the line will make mistakes. It is therefore rational for them to speculate on such mistakes and buy the asset as long as the probability to sell it to someone next in line is high enough. This result is very much in line with the famous 'greater fool theory' (Long et al. 1990), which suggests that rational traders buy overvalued assets in the expectation that a

\footnotetext{
${ }^{19}$ There are only two cases where traders can know their position for sure: when the offered price is the minimum or the maximum of the range of randomly drawn prices, which signal with certainty that they are at the first or last position in the sequence, respectively. For all other prices, however, traders can only infer a probability not to be last.
} 
'greater fool' down the line will mistakenly buy the asset at an even higher price. ${ }^{20}$ In fact, experimental tests show that individuals who speculate a lot in this game also produce stronger bubbles and crashes in more realistic and dynamic double auction trading environments (Janssen et al. 2015).

\section{The Madness of Crowds}

As explained in the previous section, speculators may try to ride a bubble in the belief that there are enough fools out there to buy them out. This can be a rational strategy and there are many scientific models that explain the existence of such rational bubbles in financial markets (see Stracca (2004) for an overview). It seems that there are potentially enough greater fools out there for more professional traders to speculate on. Heterogeneous agent models in finance assume that market participants are very different, not only with respect to preferences but also in terms of market experience, financial literacy and speculative sophistication (Hommes 2006). Empirical studies show that private traders, who are considered to be less sophisticated than professional traders, do not gain from their trading on average and actually underperform after deduction of transaction costs. Instead of (noise) trading, private investors could have made more money buy simply investing into a broadly diversified stock market index and do nothing (Barber and Odean 2000).

Speculating on greater fools, however, entails the risk to exit the market too late when not enough fools are left to buy the overpriced stocks. To complicate matters it is possible that speculators feed on each other, mistaking purchases of other speculators as noise. As in the guessing game it is often hard to tell whether a winning bid was really smart or simply lucky, particularly when there is a lot of noise. Warren Buffet, one of the richest and most successful investors of all time, once warned: "Nothing sedates rationality like large doses of effortless money. After a heady experience of that kind, normally sensible people drift into behavior akin to that of Cinderella at the ball. They know that overstaying the festivitiesthat is, continuing to speculate in companies that have gigantic valuations relative to the cash they are likely to generate in the future-will eventually bring on pumpkins and mice. But they nevertheless hate to miss a single minute of what is one helluva party. Therefore, the giddy participants all plan to leave just seconds before midnight. There's a problem, though: They are dancing in a room in which the clocks have no hands." 21

\footnotetext{
${ }^{20}$ 'Greater fools' are also often called 'noise traders', because they are seen to buy and sell assets in financial markets at random, like 'white noise'. Classical examples of noise traders are inexperienced individuals who inherit some money and decide to invest it in some random portfolio in the stock market.

${ }^{21}$ Warren Buffet, Letter to the Shareholders of Berkshire Hathaway Inc., 2000, p. 14.
} 


\subsection{Luck Versus Skill}

This raises the question how speculators can be viewed as professional rational agents who exploit noise traders and, at the same time, as 'giddy Cinderellas' who miss the point of exit. The answer is that, although professional traders and sophisticated speculators may not be greater fools, even they cannot beat the market in the long run, which makes them fools, too; maybe lesser fools, but fools after all. This notion is a direct implication of the efficient market hypothesis (EMH), which states that nobody can systematically beat the market. The value of a financial asset is defined by its expected future cash flow, discounted to its present value. Through the market mechanism, all relevant forecasts of market participants are compounded in market prices. If financial markets are efficient, which means that all information about possible future states of nature and cash flows are impounded in market prices instantaneously, then the residual price movements must be triggered by genuine surprises, which nobody has seen coming and which are therefore, by definition, a random walk (Fama 1965).

For a graphic representation, let's extend the Galton board in Figure 0 to 1000 rows of pegs, run a couple of balls through it and track their paths. Figure 3 shows some of the random walks of these balls, turned by $90^{\circ}$ so that they now 'fall' horizontally along the X-axis of 1000 pegs. Remember that this is equivalent to a 1000 coin tosses in which we can either lose or gain a dollar. Most random walks will deviate substantially and for longer periods from wealth levels of zero. Two thirds can deviate as far as \pm 31.70 dollars, indicated by the two dotted lines, which are defined by $\sigma \times \sqrt{n}$ : the standard deviation of the coin toss $(\sigma=1)$ and the number of tosses $(n=1000)$. One third of all random walks will deviate at some point to wealth levels above and below $\sigma \times \sqrt{n}$, as the two outliers show with wealth levels of \pm 100 dollars. $^{22}$

As the EMH predicts, the random walks in Fig. 3 have a high resemblance with stock price charts. In fact, some surveys indicate that stock market traders and other financial professionals cannot reliably tell the difference between random walks and real stock price developments (Siegel 2013). Many studies in financial economics show that the performance of the vast majority of financial professionals is due to (random) luck and not skill (Fama and French 2010; Malkiel 1995). Luck to be active in a certain period and in a certain class of investments. As a famous multi-annual experiment by the Wall Street Journal showed there is a very high likelihood that a dart-throwing monkey is an equally 'skilled' stock market forecaster as professional investment advisers (Porter 2005). If an investment manager

\footnotetext{
${ }^{22}$ Theoretically, if enough red balls fall through the Galton board, 1000 pegs or coin flips can produce a sequence of 1000 heads, leading to a final wealth of 1000 dollar. This is equivalent to Émile Borel's infinitely typewriting ape, published in 1913. At one point in time, by chance, this ape will have produced the Bible or Hamlet or any other finite text.
} 


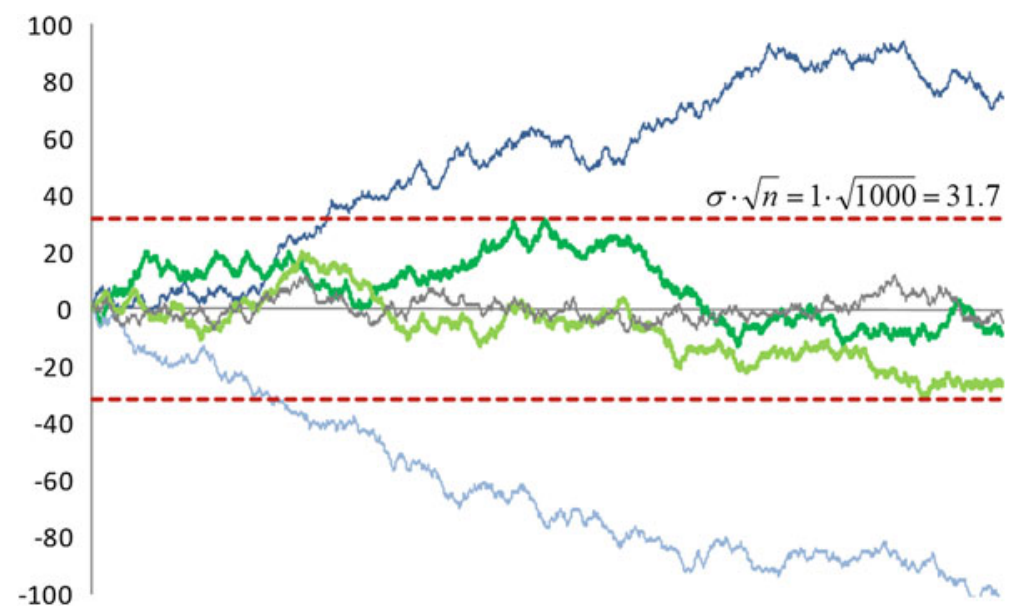

Fig. 3 Random walks

has an exceptional track record of past investments, there is a good chance that we have met the upper outlier random walk in Fig. 3 and not somebody who can consistently predict super-investments that others simply did not see. The catch with random walks is that the expected value of all future coin flips does not change and always remains zero, no matter at which point we currently are. This is what mathematicians and finance scholars call a 'martingale': at each point in a realized random sequence, the conditional expectation of the next value in the sequence is equal to the current value, irrespective of the preceding sequence. The martingale property of asset returns in efficient financial markets is the reason why governments warn clients that past investment performance provides no indication for the future. Unfortunately, too many investors believe that significant positive deviations from the $\mathrm{X}$-axis are a signal of skill and not luck (Hoffmann and Post 2014). ${ }^{23}$ In doing so, they fall prey to the self-attribution bias, which is the tendency to attribute success to one's own disposition and failure to external forces (Miller and Ross 1975; Feather and Simon 1971).

The prevalence of the EMH is the reason why traders say that there is "no free lunch at Wall Street'. You cannot simply predict future stock prices from some charts (its preceding sequence) and make some easy money. Even news, when publicly available, cannot be used as forecasting and trading advantage as it is almost instantaneously compounded in the market price. In many financial markets computer algorithms are involved in more than half of all financial transactions. Algorithms trade in milliseconds, impounding new information in prices much

\footnotetext{
${ }^{23}$ For a vivid description of the pitfalls of randomness that financial traders falls prey to, also see Nassim Nicholas Taleb's bestseller 'Fooled by randomness' (Taleb 2005).
} 
quicker than any human trader could, which has a positive effect on the informativeness of prices (Chaboud et al. 2014). ${ }^{24}$

The bottom line is, that efficient financial markets are very good in 'producing' random walks. There is a broad consensus in the academic finance communityincluding many critics of the EMH - that, because of the efficiency of most financial markets, it is very hard, if not impossible, for traders to systematically beat the market (Stracca 2004). ${ }^{25}$ In the end we are all greater or lesser fools in light of the self-produced randomness on financial markets.

\subsection{No Free Lunch $\neq$ the Price Is Right}

The EMH is probably the most powerful and, at the same time, most hotly debated principle in Finance. This was demonstrated in 2013, when the Nobel Prize in Economics was awarded to three eminent scholars: Eugene Fama, father of the EMH; Robert Shiller, an outspoken critic of the EMH, and Lars Peter Hansen, who offered an econometric compromise between the two. The EMH has two implications: one is that we cannot beat the market (no free lunch); the other is that, because of this informational efficiency, the market price we observe is a correct estimate of a financial asset's future cash flows a.k.a. its fundamental or intrinsic value (the price is right). The former looks at price changes (returns), the latter at price levels. In the former we are in a world of arbitrage which exploits temporary differences between prices. ${ }^{26}$ In the latter we are in a world of market timing, over-/undervaluation and mean reversion, which exploit differences to fundamental values. It is the latter of the two worlds in which we believe to observe 'madness' in markets: bubbles and crashes that - with hindsight — seem to be everything but 'the right price'. ${ }^{27}$ As much as financial scholars agree on the former, that we cannot beat the market, they are critical about the latter, the claim that the price is always right (Stracca 2004).

\footnotetext{
${ }^{24}$ The implications of algorithmic trading for social welfare are less clear. The informational efficiency by speeding up price discovery with machines may not be socially efficient if traders overinvest in technology due to adverse selection (Biais et al. 2011).

${ }^{25}$ This insight has led to the phenomenal growth of index funds, which specialize in automatic and therefore very cost-effective investments in large, diversified index portfolios (the market return), without the pretense of being able to beat the market.

${ }^{26} \mathrm{~A}$ classic example is triangular arbitrage in currency markets. If we pay 2 euro for 1 dollar, 1 dollar for 1 pound, and 1.5 euro for 1 pound, then it makes sense to buy pounds with euros (1.5:1), sell pounds for dollars (1:1), and sell dollars for euros (1:2) until all three exchange rates are perfectly balanced.

${ }^{27}$ A prominent example is the 'tulipmania' in March 1637 in the United Provinces (now the Netherlands), where a single tulip bulb reached prices of more than 3000 guilders (florins), which was about 10 times the annual income of a skilled craftsman. Note that many of the peak prices were quoted in futures contracts which were later changed by decree into options contracts. Thus, despite extreme price quotes, it is questionable whether much money had changed hands between buyers and sellers (Thompson 2006).
} 
To unravel this apparent contradiction we have to understand that the EMH rests on three, progressively weaker conditions, any one of which will lead to market efficiency: (i) full rationality, (ii) independent deviations from rationality, and (iii) unlimited arbitrage (Shleifer 2000). Proponents of the EMH argue that, even if conditions (i) and (ii) do not hold, which is widely accepted, any systematic pricing errors (biases) will be arbitraged away by more sophisticated traders. Critics of the $\mathrm{EMH}$ argue that the potential of arbitrageurs to reduce mispricing is limited: arbitrage is not riskless, in many situations there exist severe liquidity constraints to arbitrage against the market, and arbitrage requires substantial investments in ICT, real-time data, and human capital to succeed in a very competitive business (Shleifer and Vishny 1997). Hence, even if there is no free lunch, because the market does not offer any feasible arbitrage opportunities, this does not necessarily lead to a convergence of prices to fundamental values (Stracca 2004). This has been demonstrated by Robert Shiller, who is well-known for his early warnings of a housing price bubble in a comparatively inefficient market with very limited arbitrage possibilities. ${ }^{28}$ A related criticism is that arbitrage is limited, because arbitrageurs themselves are boundedly rational. Then less rational traders (greater fools) are driven out of the market by more rational traders (lesser fools) so that nobody can beat the market anymore, but this does not exclude that assets are mispriced. Overall, "the existence of a pricing bias due to behavioral factors is indeed fully compatible with rational expectations and a random walk behavior of asset prices" (Stracca 2004 p. 395).

\subsection{From Mispricing to Madness}

An important difference between economics and natural sciences is that today's economic decisions and actions depend on today's beliefs and expectations about the future (which again can differ from tomorrow's belief about the future). The predictions, expectations or beliefs of agents about the future are part of a highly endogenous, dynamic and nonlinear feedback system which requires a theory of expectations (Hommes 2013). An early and mathematically very elegant theory of expectations was the rational expectations hypothesis (Muth 1961; Lucas Jr 1972):

\footnotetext{
${ }^{28}$ Accordingly, Shiller calls for more financial innovation that allow trading of risks that really matter: "Had there been a well-developed real estate market before the financial crisis of 2008, it would plausibly have reduced the severity of the crisis, because it would have allowed, even encouraged, people to hedge their real estate risks. The severity of that crisis was substantially due to the leveraged undiversified positions people were taking in the housing market, causing over 15 million US households to become underwater on their mortgages, and thus reducing their spending. There is no contradiction at all in saying that there are bubbles in the housing market and yet saying that we ought to create better and more liquid markets for housing" (Shiller 2014, p. 1511).
} 
under assumptions of rationality this hypothesis provides a rational expectations equilibrium (REE), where expectations and realizations, on average, coincide. Theoretically, in an efficient market with risk neutral agents, prices correctly reflect all possible future states of an asset's cash flows (discounted at the risk free rate) and their true, physical (objective) probabilities. Hence, from efficient risk neutral market prices we can infer state price probabilities that coincide with objective probabilities. $^{29}$

The REE refers to situations where we play Roulette with well-defined states, probability distributions and expected values. We refer to this kind of uncertainty as risk. Risk can be seen as a very special case of uncertainty, but it is not the norm. Most decisions in life are taken without knowing objective probabilities or all possible states, often referred to as ambiguity (Wakker 2010). Ambiguous situations provide a fertile breeding ground for very heterogenous beliefs and expectations (Stahl 2013) which agents have to learn about. As learning is not perfect, boundedly rational systems can be complex, nonlinear and dynamic (Hommes 2013). In such an environment, strategic uncertainty about the beliefs and behavior of others can easily create nonlinear feedback cycles. This would not be a problem if the system eventually converges to the REE. ${ }^{30}$ There are many examples, however, where bounded rationality leads to deterministic chaos that makes predictions virtually impossible and forecasts become practically random. Econometric time series studies did not succeed in ruling out randomness in stock price data (or deterministic chaos) and there is strong evidence for nonlinear dependence (Hommes 2013). Hence, while fully informed rational expectations are self-fulfilling in the REE, less informed prophecies can also be self-fulfilling in boundedly rational systems under ambiguity.

A typical example of such a feedback cycle are situations where fundamental values themselves are affected by market evaluations. To illustrate this, take a look at the market price of Tesla Motors as shown in Fig. 4. In mid 2014, the electric car company is trading at a market value of more than half that of General Motors, Ford, and Honda. Each of those established companies had more than 50 times the annual revenues as Tesla. "Pure electric cars remain a niche market, making up $<1 \%$ of total U.S. car sales. And within that, Tesla is a niche product. Its Model S

\footnotetext{
${ }^{29}$ When markets reflect risk aversion, state price probabilities for undesirable (desirable) states are higher (lower) than objective probabilities (Bossaerts and Oedegaard 2000). The equivalent martingale measure (EMM) is a probability measure in mathematical finance that adjusts the observed state price probabilities of future outcomes such that they incorporate investors' risk preferences. The EMM is a central tool in arbitrage pricing. It reflects the probability distribution under which all possible bets are fair given complete markets and no-arbitrage conditions.

${ }^{30}$ Attempts by finance theorists to reconcile evidence of individual non-rational behavior with aggregate rationality at the market level through learning and evolutionary selection has proved difficult as they required a number of demanding conditions (see Sect. 5.2 and Stracca (2004) for a discussion).
} 


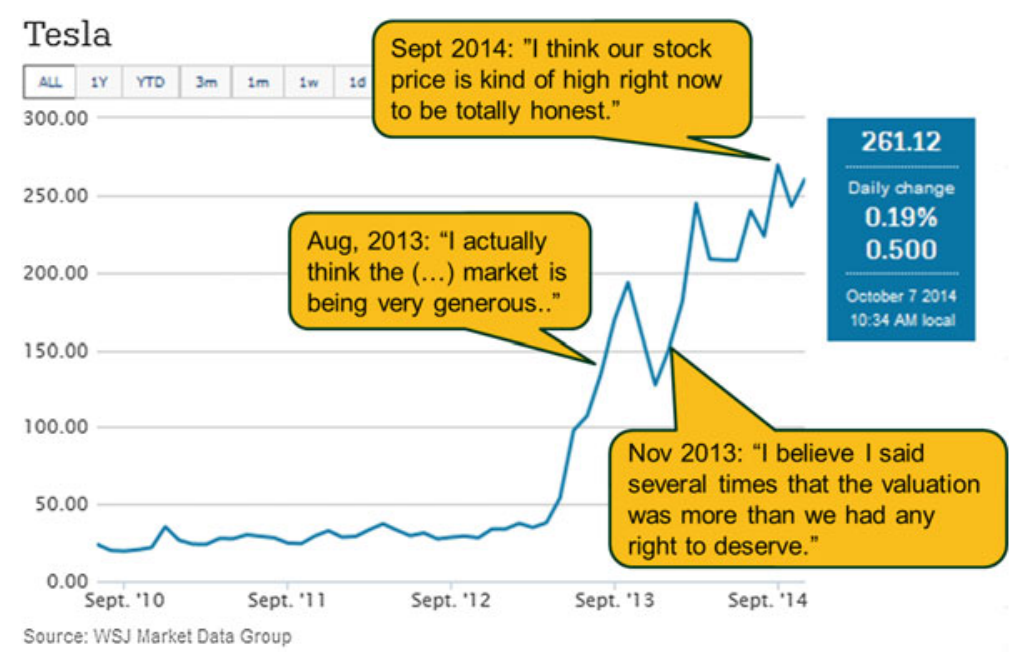

Fig. 4 Stock price of Tesla motors, 2010-2014

costs about $\$ 75,000$, while prices for the Leaf start around $\$ 30,000$ and the Volt around \$35,000. ${ }^{31}$ Moreover, in 2014 Tesla sold less e-cars than Nissan. ${ }^{32}$

Is Tesla a bubble? Interestingly, Tesla's CEO himself, Elon Musk, repeatedly remarked that he considered the stock to be overvalued (see quotes in Fig. 4). Indeed, there are indications that the price is partially driven by speculation. ${ }^{33}$ It may therefore be rational, albeit risky, for investors to ride the bubble as long as others are still buying. In support of the latter, apparently many people believe that Tesla will lead a revolution in the car industry. In fact, the high share price, possibly also driven by pure financial speculation, provided enough funding for Tesla to make some very expensive investments in potentially game-changing projects. ${ }^{34}$ Thus, if shareholders' beliefs have been over-optimistic originally, precisely this deviation from otherwise rational expectations, possibly reinforced by rational speculation, may have provided Tesla with the necessary capital to make their beliefs more realistic.

Even with hindsight it will be difficult to disentangle the underlying effects in Tesla's stock price development. "There is often a tendency (probably because

\footnotetext{
${ }^{31}$ According to marketwatch.com, Oct 3, 2014 2:59 p.m. ET.

${ }^{32}$ In September 2014, the most sold e-car was Nissan Leaf (2881 units), followed by Tesla's Model S (1650 units) and Chevrolet's Volt (1394) and BMW's 3i (1022).

${ }^{33}$ In a cryptic tweet in October 2014, Musk mentioned "D and something else". As a popular investor news site, MarketWatch.com, reported, "Musk's cryptic tweets last Thursday - and the rampant speculation they have fueled since - have pushed Tesla (...) shares about $9 \%$ higher from their Wednesday close."

${ }^{34}$ Tesla announced that they invest 5 billion US\$ in a lithium-ion battery Gigafactory with a planned production that exceeds the world capacity of 2013. Tesla also embarked on building an ambitious network of Supercharger stations along roads to facilitate longer distance journeys.
} 
economists are themselves affected by hindsight bias) to regard a certain development caused by market developments as unavoidable (supporting the idea of exogenous rationality). But it can sometimes be the result of a self-fulfilling spiral in which the prime mover is indeed an 'endogenous' market whimsical move. (...) The issue of the feedback mechanism seems most relevant in this respect. Thus far, there has been no systematic attempt to address the issue of the feedback from market prices to fundamentals, and only some informal speculations have been provided (Shiller 2000a, b; Daniel et al. 2002)" (Stracca 2004, p. 397).

\section{Conclusion}

Interactions between people are rich in randomness, consciously produced or unintended. The fertilization of economics and finance with psychological ideas and evidence allows for new insights in dealing with randomness in human interactions, but it also adds to the risk of being less parsimonious (Tirole 2002). A useful feature of many game theoretical models and the classical REE is that they impose a strong discipline on the degrees of freedom in economic models. Boundedly rational models run the risk of incorporating too much randomness and freedom as if anything goes. "To avoid 'ad hoccery', a successful bounded rationality research program needs to discipline the class of expectations and decision rules" (Hommes 2013, p. 9). In doing so, and in order to understand 'madness' in markets, more investigation in social psychology rather than individual psychology is needed. We need to understand how randomness can be channeled at the aggregate level in social and economic systems, for example through the synchronization of expectations with improved market structures and communication (see, e.g., Shiller 2000a, b).

Open Access This chapter is distributed under the terms of the Creative Commons Attribution-Noncommercial 2.5 License (http://creativecommons.org/licenses/by-nc/2.5/) which permits any noncommercial use, distribution, and reproduction in any medium, provided the original author(s) and source are credited. The images or other third party material in this chapter are included in the work's Creative Commons license, unless indicated otherwise in the credit line; if such material is not included in the work's Creative Commons license and the respective action is not permitted by statutory regulation, users will need to obtain permission from the license holder to duplicate, adapt or reproduce the material.

\section{References}

Barber, B. M., \& Odean, T. (2000). Trading is hazardous to your wealth: The common stock investment performance of individual investors. The Journal of Finance, 55(2), 773-806.

Biais, B., Foucault, T., \& Moinas, S. (2011). Equilibrium high frequency trading. Manuscript. Retrieved August 17, 2012. 
Bossaerts, P. L., \& Oedegaard, B. A. (2000). Lectures on Corporate Finance. Singapore: River Edge, New Jersey: World Scientific Pub Co Inc.

Camerer, C. F., Ho, T.-H., \& Chong, J.-K. (2004). A cognitive hierarchy model of games. The Quarterly Journal of Economics, 119(3), 861-898.

Carlsson, H., \& Damme, Ev. (1993). Global games and equilibrium selection. Econometrica, 61(5), 989-1018.

Chaboud, A. P., Chiquoine, B., Hjalmarsson, E., \& Vega, C. (2014). Rise of the machines: Algorithmic trading in the foreign exchange market: Rise of the machines. The Journal of Finance, 69(5), 2045-2084.

Daniel, K., Hirshleifer, D., \& Teoh, S. H. (2002). Investor psychology in capital markets: Evidence and policy implications. Journal of Monetary Economics, 49(1), 139-209.

De Bondt, W. F. M., \& Thaler, R. (1985). Does the stock market overreact? The Journal of Finance, 40(3), 793-805.

Doya, K. (2007). Bayesian brain: Probabilistic approaches to neural coding. Cambridge: MIT Press.

Fama, E. F. (1965). Random walks in stock-market prices. Financial Analysts Journal, 21, 55-59.

Fama, E. F., \& French, K. R. (2010). Luck versus Skill in the cross-section of mutual fund returns. The Journal of Finance, 65(5), 1915-1947.

Feather, N. T., \& Simon, J. G. (1971). Attribution of responsibility and valence of outcome in relation to initial confidence and success and failure of self and other. Journal of Personality and Social Psychology, 18(2), 173-188.

Gigerenzer, G., \& Selten, R. (Eds.). (2002). Bounded rationality: The adaptive toolbox (reprint edition). Cambridge, MA: The MIT Press.

Gilovich, T., Vallone, R., \& Tversky, A. (1985). The hot hand in basketball: On the misperception of random sequences. Cognitive Psychology, 17(3), 295-314.

Hoffmann, A. O. I., \& Post, T. (2014). Self-attribution bias in consumer financial decision-making: How investment returns affect individuals' belief in skill. Journal of Behavioral and Experimental Economics, 52, 23-28.

Hommes, C. (2013). Behavioral rationality and heterogeneous expectations in complex economic systems. Cambridge: Cambridge University Press.

Hommes, C. H. (2006). Heterogeneous agent models in economics and finance, Chapter 23. In L. Tesfatsion \& K. L. Judd (Eds.), Handbook of computational economics (Vol. 2, pp. 11091186). Elsevier.

Janssen, D.-J., Weitzel, U., \& Füllbrunn, S. (2015). Speculative bubbles-an introduction and application of the speculation elicitation task (SET). SSRN Scholarly Paper ID 2577867, Social Science Research Network, Rochester, NY.

Kahneman, D. (2003). Maps of bounded rationality: Psychology for behavioral economics. The American Economic Review, 93(5), 1449-1475.

Kahneman, D., \& Tversky, A. (1973). On the psychology of prediction. Psychological Review, $80(4), 237-251$.

Laplace, P. (1814). A philosophical essay on probabilities.

Li, T.-Y., \& Yorke, J. A. (1975). Period three implies chaos. The American Mathematical Monthly, 82(10), 985-992.

Long, J. B. D., Shleifer, A., Summers, L. H., \& Waldmann, R. J. (1990). Noise trader risk in financial markets. Journal of Political Economy, 98(4), 703-738.

Lucas, R. E, Jr. (1972). Expectations and the neutrality of money. Journal of Economic Theory, 4(2), 103-124.

Malkiel, B. G. (1995). Returns from investing in equity mutual funds 1971 to 1991 . The Journal of Finance, 50(2), 549-572.

May, R. M. (1976). Simple mathematical models with very complicated dynamics. Nature, 261(5560), 459-467.

McKelvey, R. D., \& Palfrey, T. R. (1992). An experimental study of the centipede game. Econometrica, 60(4), 803-836. 
McKelvey, R. D., \& Palfrey, T. R. (1995). Quantal response equilibria for normal form games. Games and Economic Behavior, 10(1), 6-38.

Mckelvey, R. D., \& Palfrey, T. R. (1998). Quantal response equilibria for extensive form games. Experimental Economics, 1(1), 9-41.

Miller, D. T., \& Ross, M. (1975). Self-serving biases in the attribution of causality: Fact or fiction? Psychological Bulletin, 82(2), 213-225.

Moinas, S., \& Pouget, S. (2013). The bubble game: An experimental study of speculation. Econometrica, 81(4), 1507-1539.

Moulin, H. (1986). Game theory for the social sciences (revised edition). New York: NYU Press.

Muth, J. F. (1961). Rational expectations and the theory of price movements. Econometrica, 29(3), 315-335.

Nagel, R. (1995). Unraveling in guessing games: An experimental study. The American Economic Review, 85(5), 1313-1326.

Olsen, R. A. (1998). Behavioral finance and its implications for stock-price volatility. Financial Analysts Journal, 54(2), 10-18.

Osborne, M. J. (2003). An introduction to game theory (1st edition). New York: Oxford University Press.

Porter, G. E. (2005). The long-term value of analysts' advice in the wall street journal's investment dartboard contest. Journal of Applied Finance, 14(2), Fall/Winter 2004.

Ruelle, D., \& Takens, F. (1971). On the nature of turbulence. Communications in Mathematical Physics, 20(3), 167-192.

Sargent, T. J. (1993). Bounded rationality in macroeconomics: The arne ryde memorial lectures. OUP Catalogue: Oxford University Press.

Shermer, M. (2012). The believing brain-how we construct beliefs and reinforce them as truths. New York: St. Martin's Griffin.

Shiller, R. J. (2000a). Irrational exuberance. Princeton: Princeton University Press.

Shiller, R. J. (2000b). Measuring bubble expectations and investor confidence. Journal of Psychology and Financial Markets, 1(1), 49-60.

Shiller, R. J. (2014). Speculative asset prices. American Economic Review, 104(6), 1486-1517.

Shleifer, A. (2000). Inefficient markets: An introduction to behavioral finance. Oxford, U.S.A: Oxford University Press.

Shleifer, A., \& Vishny, R. W. (1997). The limits of arbitrage. The Journal of Finance, 52(1), 35-55.

Siegel, J. J. (2013). Stocks for the long run: The definitive guide to financial market returns \& long-term investment strategies (5th ed.). New York: McGraw-Hill.

Simon, H. A. (1955). A behavioral model of rational choice. The Quarterly Journal of Economics, 69(1), 99-118.

Stahl, D. O. (2013). Heterogeneity of ambiguity preferences. Review of Economics and Statistics, 96(4), 609-617.

Stracca, L. (2004). Behavioral finance and asset prices: Where do we stand? Journal of Economic Psychology, 25(3), 373-405.

Taleb, N. N. (2005). Fooled by randomness: The hidden role of chance in life and in the markets (2nd updated edition). New York: Random House Trade Paperbacks.

Thompson, E. A. (2006). The tulipmania: Fact or artifact? Public Choice, 130(1-2), 99-114.

Tirole, J. (2002). Rational irrationality: Some economics of self-management. European Economic Review, 46(4-5), 633-655.

Tversky, A., \& Kahneman, D. (1971). Belief in the law of small numbers. Psychological Bulletin, 76(2), 105-110.

Tversky, A., \& Kahneman, D. (1974). Judgment under uncertainty: Heuristics and biases. Science, 185(4157), 1124-1131.

Wakker, P. P. (2010). Prospect theory: For risk and ambiguity. Cambridge, NY: Cambridge University Press. 